\title{
Application of Two-Channel Principle in Measuring Devices to Compensate for Disturbing Influences of Unknown Physical Nature
}

\author{
V.N. Nesterov ${ }^{1,2,3}$, A.R. Li ${ }^{1}$ \\ ${ }^{1}$ JCS Samara Electromechanical Plant, \\ Stepan Razin str., 16, Samara 443099, Russia \\ ${ }^{2}$ Samara National Research University, \\ Moskovskoe highway, 34A, Samara 443086, Russia \\ ${ }^{3}$ Povolzhskiy State University of Telecommunications and Informatics, \\ L. Tolstoy str., 23, Samara 443010, Russia
}

Received 28.01.2020

Accepted for publication 05.06.2020

\begin{abstract}
The article notes the advantages of the method of constructing absolutely invariant measuring transducers for working in conditions with disturbing influences. However, this method is not universal. Its limitations are due to the impossibility of "symmetric" transmission of all disturbing influences into parallel measuring channels. A broader interpretation of the two-channel principle is proposed to overcome these limitations. The aim of the study was to substantiate and implement a method for constructing quasi-invariant measuring transducers and systems that retain their metrological characteristics under external disturbances of unknown physical nature.

The theory that develops the two-channel principle to a full-fledged technological method is presented in the article. The theory includes the necessary and sufficient conditions for physical feasibility this method. Two fundamental tasks have been solved in the work. The first task is to identify signs that reflect the essence of the technological method in to specific cases and the second is to implement a methodology that allows these signs to be effectively applied in practice.

In the examples, a complex of technologies is defined for groups of elements of quasi-invariant transducers that provide compensation of the influencing factors acting on them with acceptable accuracy.

There are significant advantages in discussed method. It gives hope for acceptable measurement results under conditions when character and even physical principle of influencing a priori are unknown.
\end{abstract}

Keywords: technological method, quasi-invariance, disturbing influences, measuring transducer.

DOI: $10.21122 / 2220-9506-2020-11-3-228-235$

\begin{tabular}{ll}
\hline Aдрес для переписки: & $\begin{array}{l}\text { Address for correspondence: } \\
\text { В.Н. Нестеров }\end{array}$ \\
Самарский национальный исследовательский университет & $\begin{array}{l}\text { Samara National Research University, } \\
\text { имени академика С.П. Королёва }\end{array}$ \\
$\begin{array}{l}\text { Московское шоссе, 34A, Самара 443086, Россия } \\
\text { e-таil: пеsterov.ntc@yandex.ru }\end{array}$ & \\
\hline Для цитирования: & For citation: \\
V.N. Nesterov, A.R. Li. & V.N. Nesterov, A.R. Li. \\
Application of Two-Channel Principle in Measuring Devices & Application of Two-Channel Principle in Measuring Devices \\
to Compensate for Disturbing Influences of Unknown Physical Nature. & to Compensate for Disturbing Influences of Unknown Physical Nature. \\
Приборы и методы измерений. & Devices and Methods of Measurements. \\
2020. - Т. 11, № 3. - С. 228-235. & 2020, vol. 11, no. 3, pp. 228-235. \\
DОI: $10.21122 / 2220-9506-2020-11-3-228-235$ & DOI: 10.21122/2220-9506-2020-11-3-228-235 \\
\hline
\end{tabular}


УДК 681.2 .088

\title{
Применение принципа двухканальности в измерительных устройствах для компенсации возмущающих воздействий неизвестной физической природы
}

\author{
В.Н. Нестеров ${ }^{1,2,3}$, А.Р. Ли ${ }^{1}$ \\ ${ }^{1}$ Самарский электромеханический завод, \\ ул. Степана Разина, 16, Самара 443099, Россия \\ ${ }^{2}$ Самарский национальный исследовательский университет имени академика С.П. Королёва, \\ Московское шоссе, 34A, Самара 443086, Россия \\ ${ }^{3}$ Поволжский государственный университет телекоммуникаций и информатики, \\ ул. Л. Толстого, 23, Самара 443010, Россия
}

Поступила 28.01.2020

Принята к печати 05.06.2020

В статье отмечены преимущества метода построения абсолютно инвариантных измерительных преобразователей для работы в условиях с возмущающими воздействиями. Однако этот метод не является универсальным. Его ограничения обусловлены невозможностью «симметричной» передачи всех возмущающих воздействий в параллельные измерительные каналы. Для преодоления названных ограничений предложена более широкая трактовка принципа двухканальности. Целью исследования являлись обоснование и реализация метода построения квазиинвариантных измерительных преобразователей и систем, которые сохраняют свои метрологические характеристики в условиях внешних возмущений неизвестной физической природы.

Представлена теория, развивающая принцип двухканальности до полноценного технологического метода, включающего необходимые и достаточные условия его физической реализуемости. В работе решены две принципиальные задачи. Первая из них заключается в выявлении признаков, отражающих сущность технологического метода применительно к конкретным случаям, вторая - в реализации методики, позволяющей эти признаки эффективно применить на практике.

В примерах определён комплекс технологических мероприятий для групп элементов квазиинвариантных преобразователей, которые обеспечивают компенсацию действующих на них влияющих факторов с приемлемой точностью.

Рассмотренный метод имеет существенные преимущества. Он даёт надежду на приемлемые результаты измерений в условиях, когда характер и даже физический принцип влияющих факторов априори неизвестны.

Ключевые слова: технологический метод, квазиинвариантность, возмущающие воздействия, измерительный преобразователь.

DOI: $10.21122 / 2220-9506-2020-11-3-228-235$

\begin{tabular}{|c|c|}
\hline $\begin{array}{l}\text { Адрес для переписки: } \\
\text { В.Н. Нестеров } \\
\text { Самарский национальный исследовательский университет } \\
\text { имени академика С.П. Королёва } \\
\text { Московское шоссе, 34A, Самара 443086, Россия } \\
\text { e-таil: nesterov.ntc@yandex.ru }\end{array}$ & $\begin{array}{l}\text { Address for correspondence: } \\
\text { V.N. Nesterov } \\
\text { Samara National Research University, } \\
\text { Moskovskoe highway, 34A, Samara 443086, Russia } \\
\text { e-mail: nesterov.ntc@yandex.ru }\end{array}$ \\
\hline $\begin{array}{l}\text { Для цитирования: } \\
V . N . \text { Nesterov, A.R. Li. } \\
\text { Application of Two-Channel Principle in Measuring Devices } \\
\text { to Compensate for Disturbing Influences of Unknown Physical Nature. } \\
\text { Приборы и методы измерений. } \\
\text { 2020. - T. 11, № 3.- - С. 228-235. } \\
\text { DOI: } 10.21122 / 2220-9506-2020-11-3-228-235\end{array}$ & $\begin{array}{l}\text { For citation: } \\
\text { V.N. Nesterov, A.R. Li. } \\
\text { Application of Two-Channel Principle in Measuring Devices } \\
\text { to Compensate for Disturbing Influences of Unknown Physical Nature. } \\
\text { Devices and Methods of Measurements. } \\
\text { 2020, vol. } 11 \text {, no. 3, pp. 228-235. } \\
\text { DOI: } 10.21122 / 2220-9506-2020-11-3-228-235\end{array}$ \\
\hline
\end{tabular}




\section{Introduction}

The problems of accuracy have been and will be relevant in measurement theory always regardless of the place, time and type of measurement. This explains the huge number of articles and their number has been increasing steadily growing as humanity expands its area of interests. The exploration of the nearest outer space and in the future deep space, oceans, technologies accompanied by various unfavorable factors, for example, in nuclear energy or chemical industry, poses new challenges to the science of measurements. New applications and operating conditions of the measuring instruments in harsh conditions accompanied by various external and internal disturbances require serious correction of the results. In order to solve these problems method of auxiliary measurements, method of reference signals, method that using tests and others have been developed [1-5]. Their correct application can significantly reduce the errors of measuring instruments in abnormal operating conditions.

To solve these problems, methods of auxiliary measurements, of reference measures, of test measures and others have been developed. Their correct application can significantly reduce the errors of measuring instruments in abnormal operating conditions. However, each method requires certain conditions to be met. If these conditions are not met, then the effectiveness of the method may be reduced. Moreover, incorrect use of the method can result in the opposite result.

For example, the method of auxiliary measurements requires knowledge of the functions of the influence of interfering quantities, the auxiliary measurements of which allow you to enter the appropriate correction. But each auxiliary channel contributes its share to the total error of the measuring device. The test method requires additional channels, which receive a measurable value, functionally associated with exemplary tests. The methods of invariance theory, which are designed to compensate for the effect on the system of external perturbations, stand out in the theory of measurements. Initially, these methods were used in the theory of automatic control. But very soon there appeared papers in which ideas were expressed on the connection between the theory of invariance and the theory of stability of measuring systems $[6,7]$. Academician B.N. Petrov formulated the two-channel principle [7], which was essentially a necessary condition for compensating external disturbing influences on measuring devices. The combination of necessary and sufficient conditions, which is based on the mentioned principle, makes it possible to formulate and implement in the corresponding structures methodical features, which form the basis of a particular method and are implemented in the corresponding class of invariant measuring devices [8-11]. The fundamental difference between the methods of the theory of invariance and the methods of automatic correction of errors is such an organization of the structure of the system that provides compensation for disturbances inside it with the general instability of the component elements.

A series of works that consistently develops the two-channel principle to the structural method, allowed covering the classes of nonequilibrium measuring bridges and voltage dividers [12]. The absolute invariance of the transformation functions of the parametric transducers with respect to the instability of the power supply was achieved for all representatives of the class. Accordingly, the expression of the error from the instability of the EMF of the power source is identically equal to zero for all representatives of the class of two-channel parametric measuring transducers:

$$
\Delta F=\frac{\partial F}{\partial U_{1}} \frac{\partial U_{1}}{\partial E} \Delta E+\frac{\partial F}{\partial U_{2}} \frac{\partial U_{2}}{\partial E} \Delta E \equiv 0,
$$

where $F$ is two-channel transducer conversion function; $U_{1}$ и $U_{2}$ are conversion functions of the first and second measuring channels; $E$ is EMF of power supply; $\Delta E$ is deviation of power supply EMF from nominal value.

However, the physical feasibility of the methodological features [12], which provide absolute invariance of the transducers with respect to the effect of influencing factors on all elements of the devices, is limited by structural or economic reasons. Sources of errors of measuring devices are instability and technological variation of parameters of all elements included in them. But it is not always possible to provide "symmetry" of the influence of these elements on measuring channels.

Further analysis of the problem led to an understanding and a wider interpretation of the twochannel principle. This made it possible to formulate methodological features the im-plementation of which leads to compensation of disturbing actions on a wider set of elements of the measuring device. A preliminary analysis of the essence of these 
methodological features allows us to propose the name of the method.

\section{Technological method for constructing quasi-invariant measuring transducers}

As already noted, the two-channel principle is a necessary but not sufficient condition for compensation of external disturbing influences on measuring devices. Therefore, a formal apparatus that develops the two-channel principle to the level of necessary and sufficient conditions the fulfillment of which due to specific technical or technological solutions will compensate for the instability of the device as a whole is the basis of the method, the name of which was set in the heading of the section.

Formal features that develop the two-channel principle to a full-fledged technological method, which includes the necessary and sufficient conditions for its physical feasibility, can be stated in the form of the following three points.

1 . There should be $q$ elements $q \geq 2$ in the system structure that are affected by disturbing factors $\zeta_{j}$.

2. It should be possible to implement special technological measures leading to the "differentialsymmetric" effect of disturbing factors on the parameters of the elements included in the system:

$$
\left\{\frac{\Delta k_{i r}\left(\zeta_{j}\right)}{k_{i r 0}}-\frac{\Delta k_{i l}\left(\zeta_{j}\right)}{k_{i l 0}}\right\} \rightarrow 0, r \neq l ; r, l \in q,
$$

where $\Delta k_{i r}\left(\zeta_{j}\right), \Delta k_{i l}\left(\zeta_{j}\right) \quad$ are deviations of the $k$-th parameter, respectively, of the $r$-th and $l$-th elements of the $i$-th conversion channel from the nominal values under the influence of disturbing factors $\zeta_{j}$.

3. The following criterion must be met:

$$
\Delta F=\sum_{i=1}^{n} \sum_{j=1}^{q} \frac{\partial F}{\partial Y_{i}} \frac{\partial Y_{i}}{\partial k_{i j}\left(\zeta_{j}\right)} \Delta k_{i j}\left(\zeta_{j}\right) \rightarrow 0,
$$

where: $F$ is resulting system conversion function; $Y_{i}$ is conversion function of $i$-th channel; $n$ is number of channels.

In the limit case if the expressions (1) turn into an identity then the criterion (2) reaches a zero extremum. Then we can talk about achieving absolute invariance of the system relative to disturbing factors. However, such a case is ideal. Therefore, the fundamental task is the methodological task of searching for paired elements and the corresponding technological measures that lead to the closest possible fulfillment of criterion (2) in each specific case. In essence, we are talking about identifying the technological "know-how" for each pair (group) of elements that make up the measuring circuit.

Based on the above the problem to be solved is divided into two. The first task is to identify signs that reflect the principle essence of the technological method in a specific case. The second task is to implement a technique that allows these signs to be effectively applied in practice.

The technique for identifying technological "know-how" is based on the use of criterion (2). Since the left part of the criterion is an expression of error the source of which is the effect of perturbing factors on the elements, then equating it to zero and carrying out the necessary transformations it is possible to find in analytical form the conditions for minimizing the this error:

$$
\frac{\Delta k_{i r}\left(\zeta_{j}\right)}{k_{i r 0}}=\frac{\Delta k_{i l}\left(\zeta_{j}\right)}{k_{i l 0}}, r \neq l ; r, l \in q .
$$

The latter will determine technological conditions, the physical essence and feasibility of which in each particular case depends on the physics of influencing factors and the structural and technological design of the device and its elements.

It should be emphasized that the fundamental issue for the implementation of the method is the possibility of identifying one or more groups of technologically similar (identical) elements in the device, where the number of elements in the group meets the requirement $q \geq 2$.

We emphasize that the fundamental issue for the implementation of the method is the possibility of identifying one or more groups of technologically similar (identical) elements in the device, where the number of elements in the group meets the requirement $q \geq 2$.

\section{The implementation of the technological method}

Let's consider the operation of the method using the example of a half-bridge two-channel transducer [13], which is shown in Figure 1. This transducer contains two differentially included primary converters 1 and 2 of the resistive type, the third converter 3 , made in the form of a resistor, a power supply 4, differential amplifiers 5, 6 and 7 and a division unit 8 . 


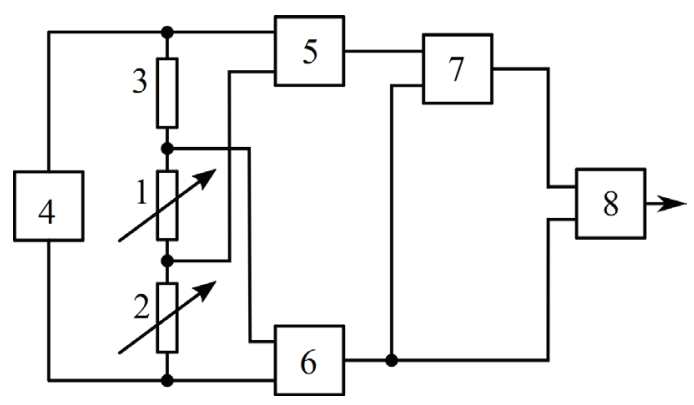

Figure 1 - Half-bridge invariant measuring transducer: 1, 2 - sensors; 3 - resistor; 4 - source of power; 5, 6, 7 differential amplifiers; 8 - division block

The signals at the outputs of differential amplifiers 5 and 6 are determined by the expressions:

$$
\begin{aligned}
& U_{1}=\frac{k_{1} E\left[\left(z_{1}+\Delta z\right)+z_{3}\right]}{\left[\left(z_{1}+\Delta z\right)+\left(z_{2}-\Delta z\right)+z_{3}\right]} ; \\
& U_{2}=\frac{k_{2} E\left[\left(z_{1}+\Delta z\right)+\left(z_{2}-\Delta z\right)\right]}{\left[\left(z_{1}+\Delta z\right)+\left(z_{2}-\Delta z\right)+z_{3}\right]},
\end{aligned}
$$

where $k_{1}$ и $k_{2}$ are transmission coefficients for voltage of differential amplifiers 5 and 6 , respectively; $\left(z_{1}+\Delta z\right)$ and $\left(z_{1}-\Delta z\right)$ are parameter values of transducers 1 and $2 ;\left(z_{1}\right.$ and $z_{2}$ are initial parameter values, and $\Delta z$ is informative increment of parameters); $z_{3}$ is converter parameter value $3 ; E$ is EMF of power supply 4.

Signals (4) and (5) are supplied to direct and inverting inputs of differential amplifier 7 , respectively. And we get a difference signal at its output, when the condition $k_{1}=k_{2}=k$ is met:

$$
U_{1}-U_{2}=\frac{k E\left[z_{3}-\left(z_{2}-\Delta z\right)\right]}{\left[\left(z_{1}+\Delta z\right)+\left(z_{2}-\Delta z\right)+z_{3}\right]} .
$$

Next, the signals (5) and (6) are processed by the division unit 8. When the condition $z_{1}=z_{2}=z_{3}=z$ is met we obtain at its output:

$F_{1}=\frac{U_{1}-U_{2}}{U_{2}}=\frac{\Delta z}{2 z}$.

Using (4), (5) and (7), we obtain:

$$
\Delta F_{1}=\frac{\partial F_{1}}{\partial U_{1}} \frac{\partial U_{1}}{\partial E} \Delta E+\frac{\partial F_{1}}{\partial U_{2}} \frac{\partial U_{2}}{\partial E} \Delta E \equiv 0 .
$$

Thus, this transducer provides absolute invariance with respect to the power supply EMF instability. However, the instability of the parameters of the remaining elements is the source of additional errors.

Based on the proposed procedure we can identify groups of technologically similar elements in the measuring transducer. These groups comprise converters $1-3$ and differential amplifiers 5 and 6 .

We will be writing an appropriately structured expression of the error from the action of influencing factors on these groups of elements in accordance with criterion (2):

$$
\begin{aligned}
& \Delta F_{1}=\frac{\left[\left(z_{1}+\Delta z\right)_{0}+z_{30}\right]}{\left[\left(z_{1}+\Delta z\right)_{0}+\left(z_{2}-\Delta z\right)_{0}\right]}\left\{\left(\frac{\Delta k_{1}}{k_{0}}-\frac{\Delta k_{2}}{k_{0}}\right)+\right. \\
& +\frac{\left(z_{1}+\Delta z\right)_{0}\left(z_{2}-\Delta z\right)_{0}}{\left[\left(z_{1}+\Delta z\right)_{0}+\left(z_{2}-\Delta z\right)_{0}+z_{30}\right]\left[\left(z_{1}+\Delta z\right)_{0}+z_{30}\right]}\left[\frac{\Delta\left(z_{1}+\Delta z\right)}{\left(z_{1}+\Delta z\right)_{0}}-\frac{\Delta\left(z_{2}-\Delta z\right)}{\left(z_{2}-\Delta z\right)_{0}}\right]+ \\
& +\frac{\left(z_{2}-\Delta z\right)_{0} z_{30}\left[2\left(z_{1}+\Delta z\right)_{0}+\left(z_{2}-\Delta z\right)_{0}+z_{30}\right]}{\left[\left(z_{1}+\Delta z\right)_{0}+\left(z_{2}-\Delta z\right)_{0}+z_{30}\right]\left[\left(z_{1}+\Delta z\right)_{0}+z_{30}\right]\left[\left(z_{1}+\Delta z\right)_{0}+\left(z_{2}-\Delta z\right)_{0}\right]} \times \\
& \times\left[\frac{\Delta z_{3}}{z_{30}}-\frac{\Delta\left(z_{2}-\Delta z\right)}{\left(z_{2}-\Delta z\right)_{0}}\right]+\frac{\left(z_{1}+\Delta z\right)_{0} z_{30}}{\left[\left(z_{1}+\Delta z\right)_{0}+\left(z_{2}-\Delta z\right)_{0}+z_{30}\right]\left[\left(z_{1}+\Delta z\right)_{0}+\left(z_{2}-\Delta z\right)_{0}\right]} \times \\
& \left.\times\left[\frac{\Delta z_{3}}{z_{30}}-\frac{\Delta\left(z_{1}+\Delta z\right)}{\left(z_{1}+\Delta z\right)_{0}}\right]\right\} \rightarrow 0,
\end{aligned}
$$


where $\frac{\Delta\left(z_{1}+\Delta z\right)}{\left(z_{1}+\Delta z\right)_{0}}, \frac{\Delta\left(z_{2}-\Delta z\right)}{\left(z_{2}-\Delta z\right)_{0}}, \frac{\Delta z_{3}}{z_{30}}, \frac{\Delta k_{1}}{k_{0}}, \frac{\Delta k_{2}}{k_{0}}$ are relative changes, respectively, of the parameters of elements $1,2,3$ and the transmission coefficients of differential amplifiers 5 and 6 under the action of influencing factors.

The error expression (8) will tend to zero with the "differential-symmetric" effect of destabilizing factors on the parameters of the corresponding groups of elements:

$$
\begin{aligned}
& \left\{\frac{\Delta k_{1}}{k_{0}}-\frac{\Delta k_{2}}{k_{0}}\right\} \rightarrow 0 ;\left\{\frac{\Delta\left(z_{1}+\Delta z\right)}{\left(z_{1}+\Delta z\right)_{0}}-\frac{\Delta\left(z_{2}-\Delta z\right)}{\left(z_{2}-\Delta z\right)_{0}}\right\} \rightarrow 0 ; \\
& \left\{\frac{\Delta z_{3}}{z_{30}}-\frac{\Delta\left(z_{2}-\Delta z\right)}{\left(z_{2}-\Delta z\right)_{0}}\right\} \rightarrow 0 ;\left\{\frac{\Delta z_{3}}{z_{30}}-\frac{\Delta\left(z_{1}+\Delta z\right)}{\left(z_{1}+\Delta z\right)_{0}}\right\} \rightarrow 0 .
\end{aligned}
$$

From expression (9) we obtain the conditions for compensating the influence of destabilizing factors on the corresponding groups of transducer elements:

$$
\frac{\Delta k_{1}}{k_{0}}=\frac{\Delta k_{2}}{k_{0}} ; \quad \frac{\Delta\left(z_{1}+\Delta z\right)}{\left(z_{1}+\Delta z\right)_{0}}=\frac{\Delta\left(z_{2}-\Delta z\right)}{\left(z_{2}-\Delta z\right)_{0}}=\frac{\Delta z_{3}}{z_{30}} .
$$

The analysis of conditions (10) allows us to determine the complex of technological measures relating to the corresponding groups of elements of the considered converter, which will provide compensation for disturbing factors acting on them with an accuracy of:

The analysis of the conditions (10) allows us to determine a set of technological measures relating to the corresponding groups of elements of the transducer considered, which will provide compensation for the disturbing factors acting on them with an accuracy up to $\varepsilon$ :

1. The elements in the group must be technologically identical. For example, they must be made of the same material, made of identical components, taken from the same batch, etc.

2. Elements of the group must be in identical conditions with respect to any disturbing influences.

3. The active elements in the group should be of the same brand, preferably from the same batch and, if possible, have a common power source.

If the listed requirements are fully fulfilled it is possible to approach the fulfillment of the conditions (10). And, accordingly, additional error of the transducer, the model of which is represented by the expression (8), will be reduced.
Expression (8) does not take into account the contribution of differential amplifier 7. Taking into account the transmission coefficient of the differential amplifier 7 after similar transformations we can (10) supplement with the condition:

$$
\frac{\Delta k_{1}}{k_{0}}=\frac{\Delta k_{2}}{k_{0}}=\frac{\Delta k_{3}}{k_{0}} .
$$

Operational amplifiers have very high input impedance that tends to infinity. There-fore, the transmission coefficients of differential amplifiers based on them are determined by the parameters of the mounted resistors. Accordingly, their instability depends on the instability of the parameters of the mounted resistors.

By revealing the technical content of the differential amplifier 7, which is shown in Figure 2, we detect a group of similar resistors 9-12, which determine its conversion function.

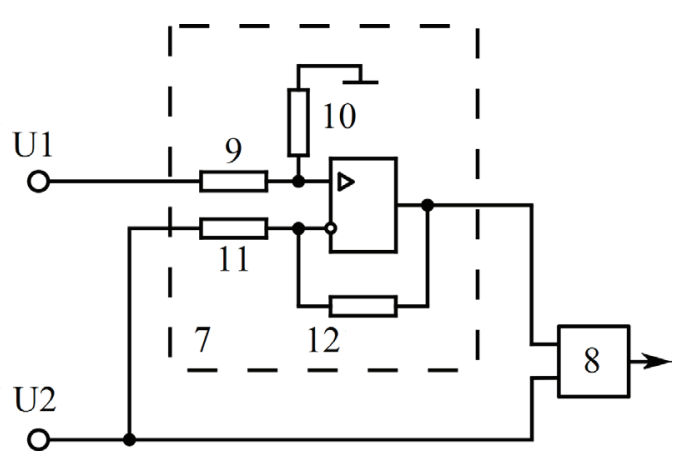

Figure 2 - Differential amplifier as part of the measuring transducer (see Figure 1): 9-12 - resistors of one type

The output voltage of differential amplifier 7 is determined by the expression:

$U_{3}=U_{1} \frac{R_{10}}{R_{9}+R_{10}}\left(1+\frac{R_{12}}{R_{11}}\right)-U_{2} \frac{R_{12}}{R_{11}}$

where $R_{9}, R_{10}, R_{11}, R_{12}$ are resistance of the resistors 9-12, accordingly.

Obviously, when the condition $R_{9}=R_{10}=R_{11}=$ $=R_{12}$ is met, the expression (11) takes the form:

$U_{3}=U_{1}-U_{2}$,

which is required in accordance with the algorithm of the circuit.

It can be seen from (11) that the instability of this differential amplifier is determined by the instability of the resistances: $R_{9}, R_{10}, R_{11}, R_{12}$. The expression of the error resulting from the instability of these resistances is as follows: 


$$
\begin{aligned}
& \Delta U_{3}=\frac{\partial U_{3}}{\partial R_{9}} \Delta R_{9}+\frac{\partial U_{3}}{\partial R_{10}} \Delta R_{10}+\frac{\partial U_{3}}{\partial R_{11}} \Delta R_{11}+\frac{\partial U_{3}}{\partial R_{9}} \Delta R_{9}+\frac{\partial U_{3}}{\partial R_{12}} \Delta R_{12}=U_{1} \frac{R_{9} R_{10}}{\left(R_{9}+R_{10}\right)^{2}}\left(1+\frac{R_{12}}{R_{11}}\right)\left[\frac{\Delta R_{10}}{R_{10}}-\frac{\Delta R_{9}}{R_{9}}\right]+ \\
& +\frac{R_{12}}{R_{11}}\left(U_{1} \frac{R_{10}}{R_{9}+R_{10}}-U_{2}\right)\left[\frac{\Delta R_{12}}{R_{12}}-\frac{\Delta R_{11}}{R_{11}}\right] .
\end{aligned}
$$

In accordance with criterion (2) from expression (12), the need for a "differentialsymmetric" effect of destabilizing factors on the parameters of the corresponding groups of resistors is revealed $R_{9}, R_{10}$ and $R_{11}, R_{12}$ :

$$
\left\{\frac{\Delta R_{10}}{R_{10}}-\frac{\Delta R_{9}}{R_{9}}\right\} \rightarrow 0 ;\left\{\frac{\Delta R_{12}}{R_{12}}-\frac{\Delta R_{11}}{R_{11}}\right\} \rightarrow 0 .
$$

Then from (13) we obtain the conditions for compensating the influence of destabilizing factors on the differential amplifier:

$$
\frac{\Delta R_{10}}{R_{10}}=\frac{\Delta R_{9}}{R_{9}} ; \frac{\Delta R_{12}}{R_{12}}=\frac{\Delta R_{11}}{R_{11}} .
$$

Conditions (14) are implemented due to technological measures:

- resistors $R_{9}, R_{10}$ and $R_{11}, R_{12}$ constituting paired groups must be technologically identical, made of the same material and on the basis of identical components, and taken from the same batch, etc.;

- resistors $R_{9}, R_{10}$ and $R_{11}, R_{12}$ constituting paired groups must be in identical conditions with respect to any disturbing influences.

Obviously, the same requirements are true for differential amplifiers 5 and 6 .

\section{Conclusion}

The presented method allows one to create circuits from unstable components that have minimal sensitivity to disturbances in harsh operating conditions. This is especially important for conditions in which the nature of these disturbances is unknown in advance.

The specific technology for bringing the devices to the most stringent fulfillment of the conditions of invariance is ensured both at the level of design of the device and at the level of technology for its manufacture. This essentially constitutes "knowhow" on a case-by-case basis.

The method discussed has a significant advantage. This method not only improves the accuracy of measuring devices in abnormal operating conditions, but gives hope for acceptable measurement results in conditions where the nature and even physical principles of influencing factors are unknown. We are talking about applications in deep space and the depths of the oceans. The method is also relevant for use in nuclear power plants, where in case of emergency situations, change sudden $\mathrm{s}$ in operating conditions are possible.

In conclusion, we note that the use of certain methods of increasing accuracy should be accompanied by a correct metrological analysis confirming the correctness and effectiveness of the measures applied. Otherwise, the result of applying the method may not meet expectations and even lead to the opposite result.

\section{References}

1. Bondarenko L.N., Nefediev D.I. [Analysis of test methods to improve measurement accuracy]. Izmerenie. Monitoring. Upravlenie. Kontrol'. [Measurement. Monitoring. Management. Control], 2014, no. 1(7), pp. 15-20 (in Russian).

2. Blockin-Mechtalin Yu.K. [Methods and instruments to improve the accuracy of measuring transducers and systems for experimental aerodynamics]. Datchiki $i$ sistemy [Sensors and systems], 2011, no. 7, pp. 8-18 (in Russian).

3. Cooper V.Ya., Rubtsov M.G. [Algorithmic methods for increasing measurement accuracy based on inverse interpolation models]. Vestnik Samarskogo gosudarstvennogo tekhnicheskogo universiteta. Seriya "Tekhnicheskie nauki" [Bulletin of Samara State Technical University. Technical Sciences Series], 2010, no. 3(28), pp. 67-72 (in Russian).

4. Ashanin V.N., Larkin S.E., Regeda O.N. [Error correction of measuring circuits of parametric sensors]. Izmerenie. Monitoring. Upravlenie. Kontrol'. [Measurement. Monitoring. Management. Control], 2016, no. 2(16), pp. 103-109 (in Russian).

5. Chekushkin V.V., Bulkin V.V. [Improving the accuracy of measuring systems with unstable parameters]. Izmeritel'naya tekhnika [Measurement Techniques], 2006, no. 1, pp. 7-11 (in Russian).

6. Ivakhnenko A.G. [The connection between the theory of invariance and the theory of stability of 
measuring systems]. Avtomatika [Automation], 1960, no. 5, pp. 35-40 (in Russian).

7. Petrov B.N., Viktorov V.A., Lunkin B.V., Sovlukov A.S. Princip invariantnosti v izmeritel'noj tekhnike [The principle of invariance in measurement technology]. Moscow, Nauka Publ., 1976, 244 p.

8. Nesterov V.N., Lee A.R. [The theory and practice of designing of invariant measurement transducers and systems based on the two-channel principle]. Izvestiya Samarskogo nauchnogo centra Rossijskoj akademii nauk [Bulletin of the Samara Scientific Center of the Russian Academy of Sciences], 2016, vol. 18, no. 4(7), pp. 14141422 (in Russian).

9. Svistunov B.L. [Measuring transducers for parametric sensors using analytical redundancy]. Izmerenie. Monitoring. Upravlenie. Kontrol'. [Measurement. Monitoring. Management. Control], 2017, no. 2(20), pp. 94-100 (in Russian).

10. Chernetsov M.V., Churakov P.P. [Invariant transformation in measuring systems with parametric sensors]. Izmerenie. Monitoring. Upravlenie. Kontrol'.
[Measurement. Monitoring. Management. Control], 2018, no. 1(23), pp. 11-17 (in Russian).

11. Keil Stefan. Technology and practical use of strain gages: with particular consideration of stress analysis using strain. Dual-channel principle, Berlin, Wiley. Ernst, Wilhelm \& Sohn (Verlag), 2017, pp. 197-200.

12. Nesterov V.N. [New class of invariant transducers: construction methods and implementation for special purpose instruments and systems]. Informacionnye, izmeritel'nye $i$ upravlyayushchie sistemy. Nauchno-tekhnicheskij sbornik Samarskogo otdeleniya Povolzhskogo centra Metrologicheskoj akademii Rossii [Information, measuring and control systems. Scientific and technical collection of the Samara branch of the Volga center of the Metrological Academy of Russia], ed. V.N. Nesterov, Samara, Samara Scientific Center of the Russian Academy of Sciences Publ., 2007, no. 3, pp. 18-37 (in Russian).

13. Nesterov V.N., Mukhin V.M. IIzmeritel'nyj preobrazovatel' [Measuring transducer]. Patent RF, no. 2297638. 2005. 